denominator of the age of the patient and the size of the cyst is probably the thickness of cystic adventitia, which is the barrier mebendazole should penetrate in order to reach the germinal layer. The cyst's adventitia is a local reaction of host tissue and pulmonary adventitias are thinner than those of liver cyts. ${ }^{4}$ This could explain the better results in the treatment of pulmonary cysts obtained by us and others. ${ }^{1}$

We have therefore been able to show in this study that high doses of mebendazole have been effective against hydatidosis of children especially in cysts of medium and small size, without serious side effects, and can be used as an alternative treatment.
1 Davis A, Pawlowski ZS, Dixon H. Multicentre clinical trials of benzimidazole carbamates in human echinococcosis. Bull WHO 1986;64:383-8.

2 Todorov T, Vutova K, Petkov D, Mechkov G, Kolev K. Albendazole treatment of human cystic echinococcosis. Albendazole treatment of human cystic
Trans $R$ Soc Trop Med Hyg 1988;82:453-9.

3 Kammerer WS, Judge DM. Chemotherapy of hydatid disease (Echinococcus granulosus) in mice with mebendazole and bithionol. Am f Trop Med Hyg 1976;25:714-7.

4 Gil Grande LA, Boixeda D, Garcia-Hoz F, et al. Treatment of liver hydatid disease with mebendazole: a prospective study of thirteen cases. Am $\mathcal{J}$ Gastroenterol 1983;78:584-8.

5 Karpathios T, Syriopoulou V, Nicolaidou P, Messaritakis J. Mebendazole in the treatment of hydatid cysts. Arch Dis Child 1984;59:894-6.

6 Woodtli W, Bircher J, Witassek F, Eckert J, Wuthrich B Amman RW. Effect of plasma mebendazole concentrations in the treatment of human echinococcosis. Am $\mathcal{J}$ Trop Med Hyg 1985;34:754-60.

\title{
Familial growth hormone releasing factor deficiency in pseudopseudohypoparathyroidism
}

\author{
H F Stirling, D G D Barr, C J H Kelnar
}

Department of Child Life and Health,

University of Edinburgh,

15-17 Hatton Place,

Edinburgh EH9 1UW

H F Stirling

D G D Barr

C J H Kelnar

\section{Correspondence to:}

\section{Dr Stirling.}

Accepted 12 November 1990

(Arch Dis Child 1991;66:533-5).
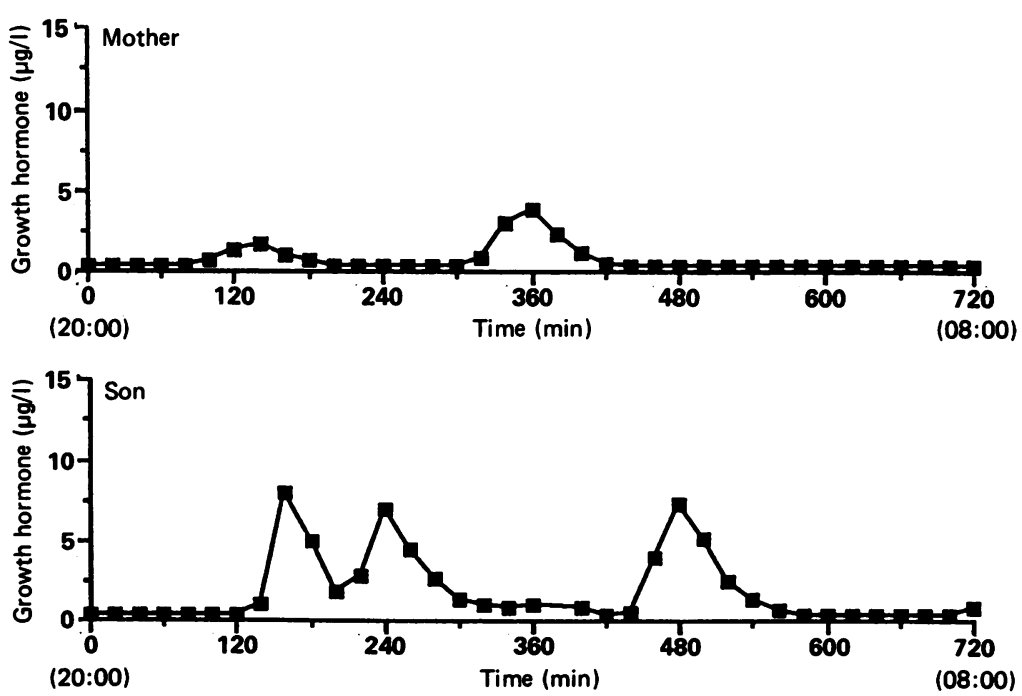

Figure 1 Overnight growth hormone secretion in mother and son. (Growth hormone comversion factor, $1 \mu \mathrm{g} / \mathrm{l}=2 \mathrm{mU} / \mathrm{l}$.)

\begin{abstract}
A mother with pseudopseudohypoparathyroidism and her short son showed poor spontaneous growth hormone secretion, and provocation tests suggested a deficiency of growth hormone releasing factor. This is the first report of growth hormone releasing factor deficiency in pseudopseudohypoparathyroidism. The boy has responded well to growth hormone treatment over a period of three years.
\end{abstract}

\section{Case reports}

A 4.5 year old healthy boy presented with short stature (height standard deviation score (SDS)

08:00)
$-3.93)$. His mother was short $(145 \cdot 2 \mathrm{~cm})$ and had clinical features of pseudopseudohypoparathyroidism (short fourth and fifth metacarpals and metatarsals, round facies). She was euthyroid but in the past had been treated with carbimazole and radioactive iodine for hyperthyroidism. The child had normal thyroid function. Both the boy and his mother were normocalcaemic with normal plasma cyclic AMP responses to parathyroid hormone stimulation.

Both mother and son had poor spontaneous overnight growth hormone secretion (fig 1). One would have expected three to four pulses of growth hormone during the night with pulse amplitude $>10 \mu \mathrm{g} / 1$ in the child. The mother failed to produce any significant growth hormone pulses. The boy's response to insulin induced hypoglycaemia was poor with a peak growth hormone concentration of $4 \cdot 1 \mu \mathrm{g} / \mathrm{l}$. The cortisol response was satisfactory. However when given growth hormone releasing factor both mother and child showed a very pronounced response: the child with a peak growth hormone concentration of $>95 \mu \mathrm{g} / \mathrm{l}$ and the mother with a concentration of $73 \mu \mathrm{g} / \mathrm{l}$.

Since the age of 5.7 years the boy has been treated with growth hormone ( $24 \mathrm{IU} / \mathrm{m}^{2} /$ week). His height SDS at the start of growth hormone treatment was $-3 \cdot 70$ with a height velocity of $4.9 \mathrm{~cm} /$ year (height velocity SDS -1.47 ). Height velocity over the first year of treatment increased to $9.1 \mathrm{~cm} /$ year (height velocity SDS $+3 \cdot 28$ ). Good growth has been maintained on growth hormone for three years and he now has a height SDS -1.95 (fig 2). Bone age has not advanced abnormally and his final height prognosis has improved. 


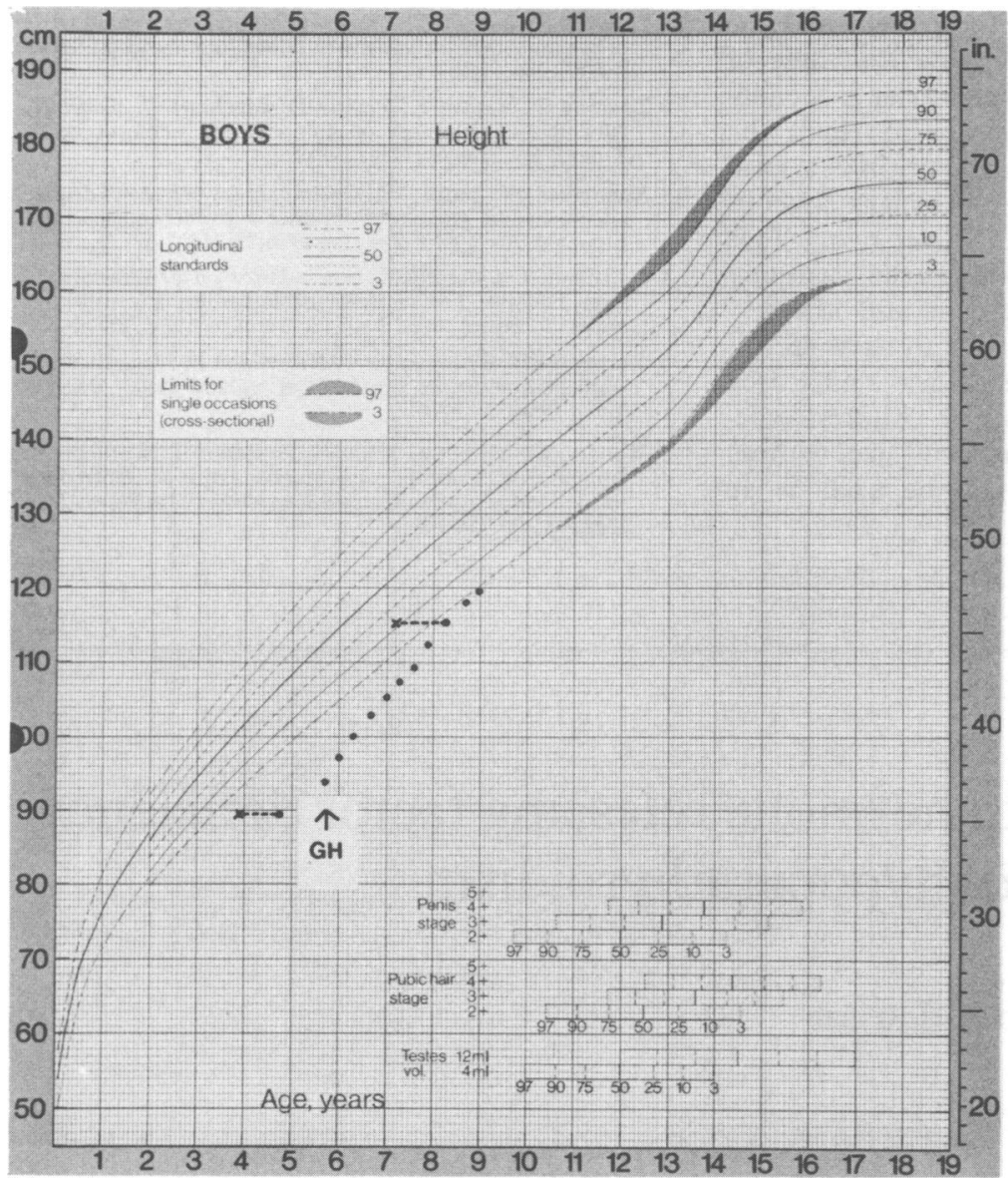

Figure 2 Growth chart of boy. metatarsals may not appear until mid-childhood or even adolescence. Thus pseudohypoparathyroidism / pseudopseudohypoparathyroidism cannot be excluded by the absence of dysmorphic features in childhood. The condition is probably autosomal dominant, so first degree relatives of known patients require careful observation. Short stature or poor height velocity may be the first indication that a child is affected.

Abnormalities of secretion of other peptide hormones, particularly thyroid and gonadotrophins, have been described in patients with pseudohypoparathyroidism, ${ }^{23}$ and it is reasonable to postulate that abnormalities of growth hormone secretion may also occur. One patient with absent growth hormone response to arginine provocation has been described. ${ }^{4}$ It is likely that there is considerable variation in growth hormone secretion as patients with pseudohypoparathyroidism can be of normal size.

Several mechanisms could be involved in the short stature of patients with pseudohypoparathyroidism. There could be defects in both growth hormone and/or growth hormone releasing factor secretion. The growth hormone releasing factor receptor protein on the somatotroph activates a coupling protein to stimulate adenylate cyclase activity and hence growth hormone synthesis and release. In pseudohypoparathyroidism the basic defect causing resistance to parathyroid hormone may be a deficiency in the guanine nucleotide regulatory protein or receptor-cyclase coupling protein. Thus in some patients with pseudohypoparathyroidism the growth hormone secretory defect may be in receptor binding for the releasing factor and/or activation of its regulatory protein, similar to that postulated for the defect in parathyroid hormone regulatory protein. ${ }^{5}$ In the family described here, however, the abnormality demonstrated is in the growth hormone releasing factor secretion rather than in its binding to the somatotroph.

This mother and child showed poor spontaneous nocturnal growth hormone secretion, with the child having an inadequate response to insulin induced hypoglycaemia. The fact that both have supramaximal responses to growth hormone releasing factor suggests that they have functioning somatotrophs, and that their defect is in the production or secretion of growth hormone releasing factor. This would lead to functional growth hormone deficiency and is likely to be the cause of the short stature in these patients. The boy has been treated successfully with growth hormone with improvement in his height prognosis. This is the first report of growth hormone releasing factor deficiency in pseudopseudohypoparathyroidism.

In conclusion-many adults and children with pseudohypoparathyroidism / pseudopseudohypoparathyroidism are conspicuously short. One should not assume that this is just part of the syndrome, as they may have an associated abnormality of growth hormone secretion. It is possible that the short stature of pseudohypoparathyroidism / pseudopseudohy- 
poparathyroidism may be treatable with growth hormone and adult height improved.

1 Monn E, Osnes JB, Oye I, Wefring WK. Pseudohypoparathyroidism-a difficult diagnosis in early childhood. Acto Paediatr Scand 1976;65:487-93.

2 Wijn EM, Steendijk R. Growth and development in a girl with pseudohypoparathyroidism and hypothyroidism. Acta Paediar Scand 1982;71:657-60.

3 Shapiro MS, Bernheim J, Gutman A, et al. Multiple abnormalities of anterior pituitary hormone secretion in association with pseudohypoparathyroidism. F Clin Endocrinol tion with pseudohypo
Metab 1980;51:483-7.

4 Shima M, Nose O, Shimizu $K$, et al. Multiple associated endocrine abnormalities in a patient with pseudohypoparathyroidism type la. Eur f Pediatr 1988;147:536-8.

5 Frohman LA, Jansson J. Growth hormone releasing hormone. Endocr Rev 1986;7:223-53.

\section{Suffocation}

Most of us have difficulty comprehending the full repertoire of human behaviour in apparently sane people and therefore most kinds of child abuse initially arouse feelings of disbelief. Deliberate suffocation of children by parents is one such but that it occurs there can be no doubt because to the best of my knowledge it is the only form of child abuse (other than ritual or pornographic abuse) which has been recorded on videotape. ${ }^{1}$ Roy Meadow ( $\mathcal{F}$ Pediatr 1990;117:351-7) has recently presented information about 27 children, each from a different family, who were abused in this way. Nine of the children died and one had severe cerebral injury. In at least 11 cases the mother was either filmed or observed suffocating the child and in the others she either confessed or was found guilty in the criminal court. The families lived in different parts of Britain and came to Professor Meadow's attention because of his widely known interest in this problem and from clinical, social work, and legal sources. Twenty four children had had previous episodes of apnoea, cyanosis, or seizures and half of those had had more than 10 such episodes. Their ages at the time of the first episode ranged from 2 weeks to 18 months and on discovery of the suffocation, from 2 to 48 months. There were 33 older siblings of whom 18 had died suddenly and unexpectedly. At necropsy 13 of these deaths had been certified as SIDS. In all 27 known cases of suffocation the mother was the perpetrator, although it is known that occasionally the father may do it. Not all of the reported episodes in the suffocated children were due to suffocation, some were fabricated reports. Some of the mothers later described feelings of hatred for the child giving as reasons the apparent contrast between their own misery and the child's happiness, or the fact that the child resembled his father, or interfered with social life or work.

The baby who presents to hospital with a history of apnoea is one of the most worrying problems in paediatrics. Most are found to be well and are sent home with or without an apnoea monitor and with such additional support to the parents as seems appropriate or feasible but inevitably some later die suddenly and we are left wondering 'could we have done more?' In most cases probably we couldn't but we must be alert to the possibility of suffocation and prepared to act in the interests of the child if the possibility seems substantial. As with all child abuse it is impossible always to run an exact course between on the one hand putting the child at risk and on the other causing suspicion to fall on innocent parents.

ARCHIVIST 